БАЗАРОВ Т. Ю., РАЙКОВ А. В., ШАЙХУТДИНОВ Р. Р.

ВОЗМОЖНОСТИ И ОГРАНИЧЕНИЯ ОПРОСНИКА «МАСТЕР ОРГАНИЗАЦИИ ГРУППОВОЙ РАБОТЫ»

РосСиЙский психологИчЕский жУРнАл, 2019, Т. 16, № 4, 56-73. doi: 10.21702/rpj.2019.4.5

\title{
Возможности и ограничения опросника «Мастер организации групповой работы»
}

\author{
Тахир Ю. Базаров ${ }^{1 *}$, Александр В. Райков ${ }^{2}$, Ринат Р. Шайхутдинов ${ }^{3}$ \\ ${ }^{1}$ Московский государственный университет имени М. В. Ломоносова, г. Москва, Российская Федерация \\ 2 Филиал Московского государственного университета имени М. В. Ломоносова в г. Ташкенте, \\ г. Ташкент, Республика Узбекистан \\ ${ }^{3}$ GM Powertrain Uzbekistan, пос. Хонобод, Ташкентская область, Республика Узбекистан \\ *E-mail: tbazarov@mail.ru
}

ORCID ID: https://orcid.org/0000-0002-1591-3932, https://orcid.org/0000-0001-8124-4602, https://orcid.org/0000-0001-6884-0960

\begin{abstract}
Аннотация
Ввеление. Концепция о трех ролях организатора групповой работы- фасилитаторе, медиаторе и модераторе, а также основанный на ней опросник («ФаМеМо»), позволяют расширить понимание психологии Аилерства. Целью Аанного исслеАования яв^яется разработка и апробация модифрицированной версии опросника, которая Аопускает внешнюю оценку компетентностей милера членами его группы.

Методы. Апробация методики производилась в рамках квазиэксперимента, в котором изуча^ось влияние компонентов компетентности организатора групповой работы на эффективность Совместной интел^ектуальной Аеятельности. А^я проверки валиАНости моАифрицированной версии инструмента использовались опросники: «Аиагностика групповой мотивации» (И. А. АаАанов), «Аиагностика Ае^ового, творческого и нравственного кАимата в кол^ективе» (Н. П. Фетискин, В.В.КозАов, Г. М. Мануй^ов), «Методика оценки психологической атмосореры в колмективе» (А. Ф. Филлер), «Метолика на определение индекса групповой сплоченности» (К. И. Сишор)», «Методика изучения предметно-Аеятельностной и социально-психологической сплоченности группы» (А. В. СиАоренков, А. А. МонАрус).

Результаты. По итогам эмпирического исслеАования на выборке из 97 человек в возрасте 18-25 ^ет выявлена нормальность распрелеления по шкале «медиатор» и отрицательная асимметрия - по шкалам «фрасилитатор» и «молератор». Зафриксирована высокая олномоментная належность шкал опросника $(0,846-0,854)$. ПосреАством структурного моделирования получены Аоказательства фракторной валиАности опросника. Выявлены и солержательно проанализированы отлельные утверждения, снижающие психометрические показатели, предложены варианты их переорормулировки. Проверены и, в основном, полтвержлены гипотезы о конвергентной валиАности шкал опросника.

ОбсужАение результатов. ПреАложенный вариант Методики продемонстрировал хорошие психометрические показатели, что определяет возможность Аиагностики компонентов компетентности мастера организации групповой работы посреАством внешней оценки участниками его группы и перспективность Аальнейшей разработки инструмента.
\end{abstract}


БАЗАРОВ Т. Ю., РАЙКОВ А. В., ШАЙХУТДИНОВ Р. Р.

ВОЗМОЖНОСТИ И ОГРАНИЧЕНИЯ ОПРОСНИКА «МАСТЕР ОРГАНИЗАЦИИ ГРУППОВОЙ РАБОТЫ»

РосСИЙСКИЙ пСИХОЛОГИЧЕСКИЙ ЖУРнАл, 2019, Т. 16, № 4, 56-73. doi: 10.21702/rpj.2019.4.5

СОЦИАЛЬНАЯ ПСИХОЛОГИЯ

\section{КАючевые слова}

групповая работа, ффасилитатор, медиатор, модератор, организационная компетентность, эмоциональная компетентность, экспертная компетентность, организационно-лилерские качества, эмоциональный лилер, кооперативность

\section{Основные положения}

$>$ концепция Т. Ю. Базарова о компонентах компетентности мастера организации групповой работы имеет теоретические и эмпирические Аоказательства, благодаря чему актуальна разработка молифиццированной версии опросника «Фаси^итатор - Медиатор - Молератор», Аопускающей стороннюю оценку лилера участниками его группы;

> прел^оженная метолика Аемонстрирует высокую належность, Аостаточную фракторную ваАИАНОСть;

> шкалы «медиатор» и «модератор» обнаруживают взаимосвязи с показателями общегрупповой мотивации, сп^оченности, психологической атмосореры, климата кол^ектива; конвергентная валиАность шкалы «фрасилитатор» нужАается в Аальнейшем исслеАовании;

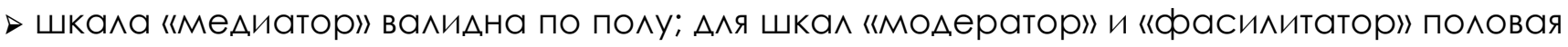
специфика не обнаружена.

\section{Для цитирования}

Базаров, Т. Ю., Райков, А. В. и Шайхутдинов, Р. Р. (2019). Возможности и ограничения опросника «Мастер организации групповой работы». Российский психологический журнал, 16(4), 56-73. doi: 10.21702/ rpj.2019.4.5

Дата получения рукописи: 02.07.2019 Дата окончания рецензирования: 08.12.2019 Дата принятия к публикации: 12.12 .2019

\section{Введение}

Как отмечает А. Л. Журавлёв, важнейшей социальной задачей является создание продуктивной системы стимулов, мотивирующих работников совместно и плодотворно трудиться, достигая общегрупповые цели и учитывая роль человека, психологические факторы, значение которых устойчиво и закономерно возрастает в современном обществе (Журавлев, 2005).

Определяющую роль команд в обеспечении успешности проекта отмечают многочисленные современные авторы (см. напр. Белбин, 2007; Богданов, 2012; Разу, 2011). Считается, что эффективное управление персоналом - это основа проектного менеджмента и главный фактор успеха его реализации (Базаров, 2011; Базаров и Ладионенко, 2017).

Эффективное ведение бизнеса во многом зависит от функционирования организационных процессов, в частности, от налаженной системы управления человеческими ресурсами. На этом уровне возникает потребность в организаторе, который обладает широким спектром методик и технологий диагностики и обучения.

С точки зрения концепции «Мастер организации групповой работы» (Базаров, 2011, 2013), можно выделить 3 базовых компонента совместной деятельности: работу на уровне личности, работу на уровне группы и работу на уровне задачи. На основе данной концепции идентифицируются три роли мастера организации групповой работы, которые различаются 
БАЗАРОВ Т. Ю., РАЙКОВ А. В., ШАЙХУТДИНОВ Р. Р.

ВОЗМОЖНОСТИ И ОГРАНИЧЕНИЯ ОПРОСНИКА «МАСТЕР ОРГАНИЗАЦИИ ГРУППОВОЙ РАБОТЫ»

РосСиЙский психологИчЕский жУРнАл, 2019, Т. 16, № 4, 56-73. doi: 10.21702/rpj.2019.4.5

СОЦИАЛЬНАЯ ПСИХОЛОГИЯ

приоритетными аспектами взаимодействия относительно каждого из компонентов совместной деятельности. Во-первых, это роль фасилитатора, для которого первоочередными ориентациями выступают группа в целом и групповые процессы. В терминологии компетентностного подхода здесь мы говорим об организационной компетентности (компетентность - это комплекс характеристик личности, ее свойств, способностей и меры ее мотивации, которые необходимы человеку для эффективной деятельности в условиях определенной компетенции (требований работы) (Базаров и Ладионенко, 2017),-nрим. aвт.). Во-вторых, это индивидуальные особенности персонала, грамотный учет которых подразумевает эмоциональную компетентность. Мастер организации групповой работы, преимущественно сосредоточенный на данной сфере, далее именуется медиатором. Проработка и анализ содержательной стороны организационных задач, которая требует интеллектуальной экспертной компетентности, отражается в деятельности модератора (Базаров, 2013). Раскроем семантику и функционал каждой роли подробнее.

\section{Роль фасилитатора}

Технология фасилитации связана с разработкой и управлением процессами и структурой группы, а также достижением результата (Мартынова, 2011). Фундаментальная характеристика фасилитатора отражается в объекте его воздействия - группой как целым, ее процессами и динамикой. Главной целью фасилитатора является достижение эффективной групповой работы. В целом функции фасилитатора заключаются: в снятии коммуникативных барьеров; в создании условий, помогающих каждому участнику быть включенным в групповое решение задачи; в выработке регламентов (этапы и правила работы), а также их контроле; в формировании и распределении командных ролей; регулировании групповых мыслительных процессов. В то же время, будучи активным в процессе взаимодействия с членами группы, фасилитатор не вмешивается в содержательный аспект работы. В методический арсенал фасилитатора входят различные способы организации совместной деятельности группы, например, мозговой штурм, групповое обсуждение и т. д. (Базаров, 2011; Базаров и Ладионенко, 2013), которые, в свою очередь, нивелируют трудности взаимодействия в группе (Штроо, 2015).

Для успешной реализации роли фасилитатора человек должен обладать набором соответствующих компетенций:

- организационно-лидерские качества - умение организовывать групповую коммуникацию и коллективную деятельность, формировать ролевую структуру группы, при этом человек должен быть активен, инициативен в этих стремлениях;

- кооперативность - знание механизмов групповой динамики; именно для фасилитатора в наибольшей степени свойственны готовность к командной работе и ориентация на партнерское взаимодействие;

- предусмотрительность - умение анализировать групповую ситуацию, конкретизировать этапы достижения совместной цели и сценировать будущее.

Кроме того, ему необходимо глубокое знание групповых процессов, таких как динамика группы, ее ролевая структура, в том числе распределение командных ролей, выстраивание эффективной коммуникации, создание правил работы с последующим контролем. Роль фасилитатора иногда характеризуют как «бессодержательную», имея в виду то обстоятельство, что фасилитатор в большей мере фокусируется на выстраивании эффективного взаимодействия, 
БАЗАРОВ Т. Ю., РАЙКОВ А. В., ШАЙХУТДИНОВ Р. Р.

ВОЗМОЖНОСТИ И ОГРАНИЧЕНИЯ ОПРОСНИКА «МАСТЕР ОРГАНИЗАЦИИ ГРУППОВОЙ РАБОТЫ»

РосСИЙСКИЙ пСИХОЛОГИЧЕСКИЙ ЖУРнАл, 2019, Т. 16, № 4, 56-73. doi: 10.21702/rpj.2019.4.5

СОЦИАЛЬНАЯ ПСИХОЛОГИЯ

нежели на содержании решаемой группой проблемы (Базаров, 2011). Организатор групповой работы в роли фасилитатора создает условия для эффективной мотивации сотрудников, стимулирует участников на совместную деятельность (Базаров, 2011; Мартынова, 2011). Способность использовать методики и технологии, а также четкое понимание теоретических моделей и принципов фасилитации рассматриваются как высший уровень компетентности фасилитатора (Bens, 2005; Schwarz, 2005).

\section{Роль медиатора}

Роль медиатора предполагает взаимодействие организатора групповой работы с участниками группы на эмоциональном уровне. Функционал лидера и/или руководителя данного стиля направлен на создание необходимых условий для личностного развития, проявления в поведении скрытых и явных личностных паттернов, необходимых при выполнении поставленной задачи. В деятельности медиатора объектом его воздействия и внимания является личность членов группы, а его функции заключаются в улучшении социально-психологического климата, создании атмосферы, необходимой для раскрытия и развития персонала. Кроме того, медиатор работает с внутренним состоянием участников (Базаров, 2011, 2013).

Компетентность медиатора включает следующие компоненты:

- влиятельность - наличие кредита доверия со стороны партнеров по коммуникации, создание внутренних условий для осуществления процессов уникализации, побуждение других к развитию; влиятельность медиатора подразумевает умение устанавливать личный эмоциональный контакт с другими людьми;

- проницательность - диагностика эмоциональных состояний других людей, оценка возможностей личностных изменений; проницательность медиатора заключается в умении и способности проявить каждого участника;

- толерантность - готовность принять различные формы самовыражения, направления индивидуального развития партнеров, умение децентрироваться; толерантность включает безоценочное невербальное поведение, способность беспристрастно принимать различные точки зрения в группе.

Чаще всего роль медиатора проявляется в конфликтных ситуациях, где он выполняет психотерапевтическую функцию, выступает посредником при разрешении проблем между участниками. Роль медиатора в группе направлена на создание оптимального для совместной деятельности социально-психологического климата. Это, в свою очередь, предполагает диагностику взаимоотношений в группе, а затем выработку групповых норм, снятие напряжения между участниками и эмоциональных конфликтов. Помощь в самосовершенствовании других людей, культивирование и закрепление личных взаимоотношений способствуют высокой эффективности взаимодействия с окружающими (Бояцис и Макки, 2007). Для этого медиатор должен эффективно исполнять следующие амплуа (Базаров, 2011, 2013):

- эмоционального лидера - человека, который выступает авторитетом для членов группы (не обязательно занимая руководящую должность);

- диагноста - человека, способного выявлять актуальное психологическое состояние группы, а также каждого участника в отдельности;

- интегратора - человека, который может сплотить группу, решив межличностные конфликты в группе.

В ряде исследований было выявлено, что эффективность процесса посредничества у людей 
БАЗАРОВ Т. Ю., РАЙКОВ А. В., ШАЙХУТДИНОВ Р. Р.

ВОЗМОЖНОСТИ И ОГРАНИЧЕНИЯ ОПРОСНИКА «МАСТЕР ОРГАНИЗАЦИИ ГРУППОВОЙ РАБОТЫ»

РосСиЙский психологИчЕский жУРнАл, 2019, Т. 16, № 4, 56-73. doi: 10.21702/rpj.2019.4.5

СОЦИАЛЬНАЯ ПСИХОЛОГИЯ

с разным уровнем эмоционального лидерства будет неодинакова. Наибольшей продуктивностью в урегулировании конфликта обладает посредник со средним и высоким уровнями контроля эмоциональной интенсивности эмоций и влияния на эмоциональные состояния людей (Базаров и Чиннова, 2012; Штроо и Серов, 2011).

\section{Роль модератора}

Роль модератора в групповом взаимодействии связана с решением поставленной задачи за счет вопросно-ответной процедуры, достижения группового плюрализма, рассмотрения ситуации с различных перспектив. Предметом работы модератора является содержание задачи, проблемы. Целью деятельности модератора является совместное решение группой поставленных вопросов, расширение арсенала способов их решения, нахождение наиболее эффективного решения (Базаров, 2011, 2013).

Для того чтобы выполнять функции модератора, организатор групповой работы должен быть экспертом в теме обсуждения (Базаров, 2011, 2013; Кричевский, 1993; Howard \& Bray, 1990). Важнейшими задачами модератора являются организация диалога - «вопросно-ответная» процедура (Сорина, 2006), создание условий для свободного обмена мнениями, для творческого совместного подхода к решению задачи (Базаров, 2011, 2013).

В процессе групповой работы функциями модератора являются:

- выявление сути вопроса;

- развитие плюрализма точек зрения у участников (Базаров, 2011; Базаров и Еремин, 2006);

- развитие креативности группы, сотворчество (Базаров, 2017);

- исключение потенциальных ошибок в рассуждениях, работа над качеством аргументов;

- развитие взаимопонимания у участников, согласование их точек зрения;

- выбор оптимального для участников способа решения проблемы;

- выработка групповой и индивидуальной ответственности за решение поставленной задачи;

- обсуждение будущего плана работы (Базаров, 2011, 2013).

Роль модератора реализуется через следующие компетенции:

- динамичность мышления - способность работать с разноплановыми интеллектуальными и практическими задачами с высокой скоростью и точностью, быстро переключаться с решения одной проблемы на другую;

- креативность - способность продуцировать необычные решения традиционных задач, поиск способов преодоления проблем, высокая вариативность решений;

- проблемная ориентация - способность отслеживать и фиксировать несогласованности в различных аспектах ситуации, формулировать продуктивные противоречия.

Для того чтобы помогать группе продвигаться в содержании, модератор сам должен обладать широким кругозором, быть в курсе современных разработок в науке и практике. Кроме того, ему необходимо быть восприимчивым к мнению участников группы, слушать и слышать ответы на задаваемые вопросы, понимать смысл ответов (Базаров, 2011).

\section{Методы}

На основе вышеизложенного теоретического конструкта был создан опросник «Мастер организации групповой работы» (автор - доктор психологических наук, профессор Т. Ю. Базаров).

Выборка. Участниками исследования выступили 97 человек (41 мужского и 56 женского пола) в возрасте от 18 до 25 лет. 
БАЗАРОВ Т. Ю., РАЙКОВ А. В., ШАЙХУТДИНОВ Р. Р.

ВОЗМОЖНОСТИ И ОГРАНИЧЕНИЯ ОПРОСНИКА «МАСТЕР ОРГАНИЗАЦИИ ГРУППОВОЙ РАБОТЫ»

РосСИЙСКИЙ пСИХОЛОГИЧЕСКИЙ ЖУРнАл, 2019, Т. 16, № 4, 56-73. doi: 10.21702/rpj.2019.4.5

СОЦИАЛЬНАЯ ПСИХОЛОГИЯ

Все респонденты были разделены на 25 групп, включавших по одному руководителю (11 мужчин и 14 женщин) и, за единичными исключениями, по 3 участника. Роль капитана команды поручалась игрокам, которые имели опыт выполнения организаторских функций. Учащиеся на одном потоке распределялись по различным группам.

Процедура. Участникам исследования было необходимо кооперативно решать интеллектуальные задания 2 типов, взятые из пособия по игре «Что? Где? Когда?» (Русанова, 1992) и теста прогрессивных матриц Равена.

Затем происходил этап опроса участников.

\section{методики:}

1. Опросник «Мастер организации групповой работы».

2. Диагностика групповой мотивации (И. Д. Ладанов) (Ладанов, 2004; Фетискин, Козлов и Мануйлов, 2002).

3. Диагностика делового, творческого и нравственного климата в коллективе (Фетискин и др., 2002).

4. Оценка психологической атмосферы в коллективе (Ф. Фидлер) (Фетискин и др., 2002).

5. Индекс групповой сплоченности (К. Сишор) (Фетискин и др., 2002).

6. Методика изучения предметно-деятельностной и социально-психологической сплоченности группы (Сидоренков и Мондрус, 2011).

Собранные данные обрабатывались в программе Microsoft Office Excel 2010, статистических пакетах SPSS15.0 и EQS6.2 for Windows.

\section{Результаты}

\section{Данные описательной статистики и надежности-согласованности}

Вначале были подсчитаны показатели описательной статистики по каждому пункту методики и величины надежности ее шкал (табл. 1).

Все шкалы обладают уровнем надежности-согласованности более 0,8, что является высоким показателем для личностных опросников (Митина, 2011).

В составе шкалы «фасилитатор» имеется единственное утверждение, удаление которого повысило бы надежность: «Фиксировал успехи, достигнутые группой в прочессе работы». Данный пункт имеет значимый отрицательный эксцесс: по-видимому, лидеры были неоднородны, и часть из них считала эту функцию необязательной, перепоручала ее секретарю и т. п.

В составе шкалы «медиатор» имеются два утверждения, слабо понижающие ее согласованность: «Помогал группе разрешать непродуктивные конфликты» и «Был склонен решать проблему на эмоциональном уровне», однако их смысл хорошо отражает конструкт, поэтому изменение не оправдано.

В составе шкалы «модератор» имеется единственный пункт, слабо понижающий ее согласованность: «Быстро и легко переключается с решения одной задачи на другую»; он обладает значительным скосом к более высоким баллам. Предположительно он недостаточно отражает содержание задач и стал бы более эффективным в формулировке «Быстро и легко переключается с решения одной интеллектуальной задачи на другую». 
БАЗАРОВ Т. Ю., РАЙКОВ А. В., ШАЙХУТДИНОВ Р. Р.

ВОЗМОЖНОСТИ И ОГРАНИЧЕНИЯ ОПРОСНИКА МАСТЕР ОРГАНИЗАЦИИ ГРУППОВОЙ РАБОТЫ»

Российский психологИчЕский жУРнАл, 2019, Т. 16, № 4, 56-73. doi: 10.21702/rpj.2019.4.5

СОЦИАЛЬНАЯ ПСИХОЛОГИЯ

\begin{tabular}{|c|c|c|c|c|c|c|}
\hline $\begin{array}{l}\text { Таблица } 1 \\
\text { Показатели описательной статистики и велич } \\
\text { методики }\end{array}$ & ны ал & ba Kpo & 5аха при & Аалени & $\wedge я \mathrm{BCex}$ & УНКTOB \\
\hline & 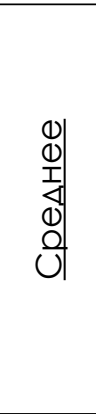 & 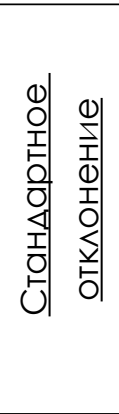 & 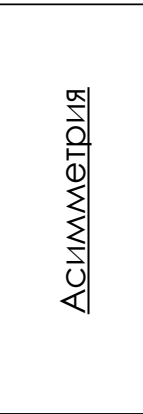 & $\begin{array}{l}u \\
y \\
0 \\
y \\
y \\
y \\
\text { (D) }\end{array}$ & 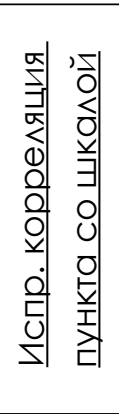 & 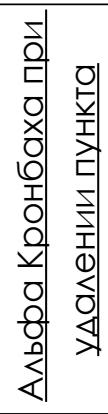 \\
\hline \multicolumn{7}{|c|}{ Шкала «фосилитатор» (a = 0,855) } \\
\hline 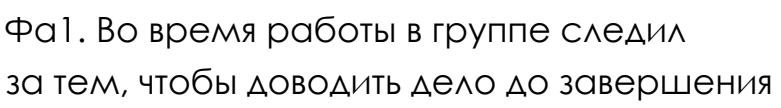 & 3,66 & 1,195 & $-0,776^{*}$ & $-0,391$ & 0,626 & 0,835 \\
\hline Фа2. Облалает талантом организатора & 3,37 & 1,007 & $-0,474$ & 0,181 & 0,686 & 0,832 \\
\hline Фа3. В ситуации группового & & & & & & \\
\hline $\begin{array}{l}\text { взаимодействия ему легко удалось } \\
\text { поАкАючить кажАого к групповой работе }\end{array}$ & 3,31 & 1,069 & $-0,394$ & $-0,615$ & 0,615 & 0,837 \\
\hline $\begin{array}{l}\text { Фа4. Замотивирова^ участников } \\
\text { на решение проблемы }\end{array}$ & 3,23 & 1,000 & $-0,349$ & $-0,095$ & 0,611 & 0,838 \\
\hline $\begin{array}{l}\text { Фа5. Прояснил общие цели и ожилаемые } \\
\text { результаты совместной Аеятельности }\end{array}$ & 3,43 & 1,185 & $-0,268$ & $-0,913$ & 0,653 & 0,833 \\
\hline Фа6. Проясни^ инАивиАуальные цели & & & & & & \\
\hline $\begin{array}{l}\text { совместной Аеятельности (цели кажАого } \\
\text { участника) }\end{array}$ & 3,12 & 1,297 & $-0,158$ & $-1,118^{*}$ & 0,495 & 0,847 \\
\hline $\begin{array}{l}\text { Фа7. Организация группового процесса - } \\
\text { олна из самых си^ьных его сторон }\end{array}$ & 3,19 & 1,098 & $-0,139$ & $-0,521$ & 0,666 & 0,832 \\
\hline Фа8. УАеля^ большое внимание & & & & & & \\
\hline $\begin{array}{l}\text { фрормальным характеристикам групповой } \\
\text { работы }\end{array}$ & 2,96 & 1,142 & $-0,047$ & $-0,632$ & 0,516 & 0,845 \\
\hline Фа9. Установи^ этапы и прави^а работы & 3,17 & 1,311 & $-0,315$ & $-1,038 *$ & 0,572 & 0,840 \\
\hline $\begin{array}{l}\text { Фа10. Фиксировал успехи, Аостигнутые } \\
\text { группой в процессе работы }\end{array}$ & 3,18 & 1,330 & $-0,250$ & $-1,038^{*}$ & 0,262 & 0,869 \\
\hline
\end{tabular}


БАЗАРОВ Т. Ю., РАЙКОВ А. В., ШАЙХУТДИНОВ Р. Р.

ВОЗМОЖНОСТИ И ОГРАНИЧЕНИЯ ОПРОСНИКА МАСТЕР ОРГАНИЗАЦИИ ГРУППОВОЙ РАБОТЫ॥

РосСИЙСКИЙ пСИХОЛОГИЧЕСКИЙ ЖУРнАл, 2019, Т. 16, № 4, 56-73. doi: 10.21702/rpj.2019.4.5

СОЦИАЛЬНАЯ ПСИХОЛОГИЯ

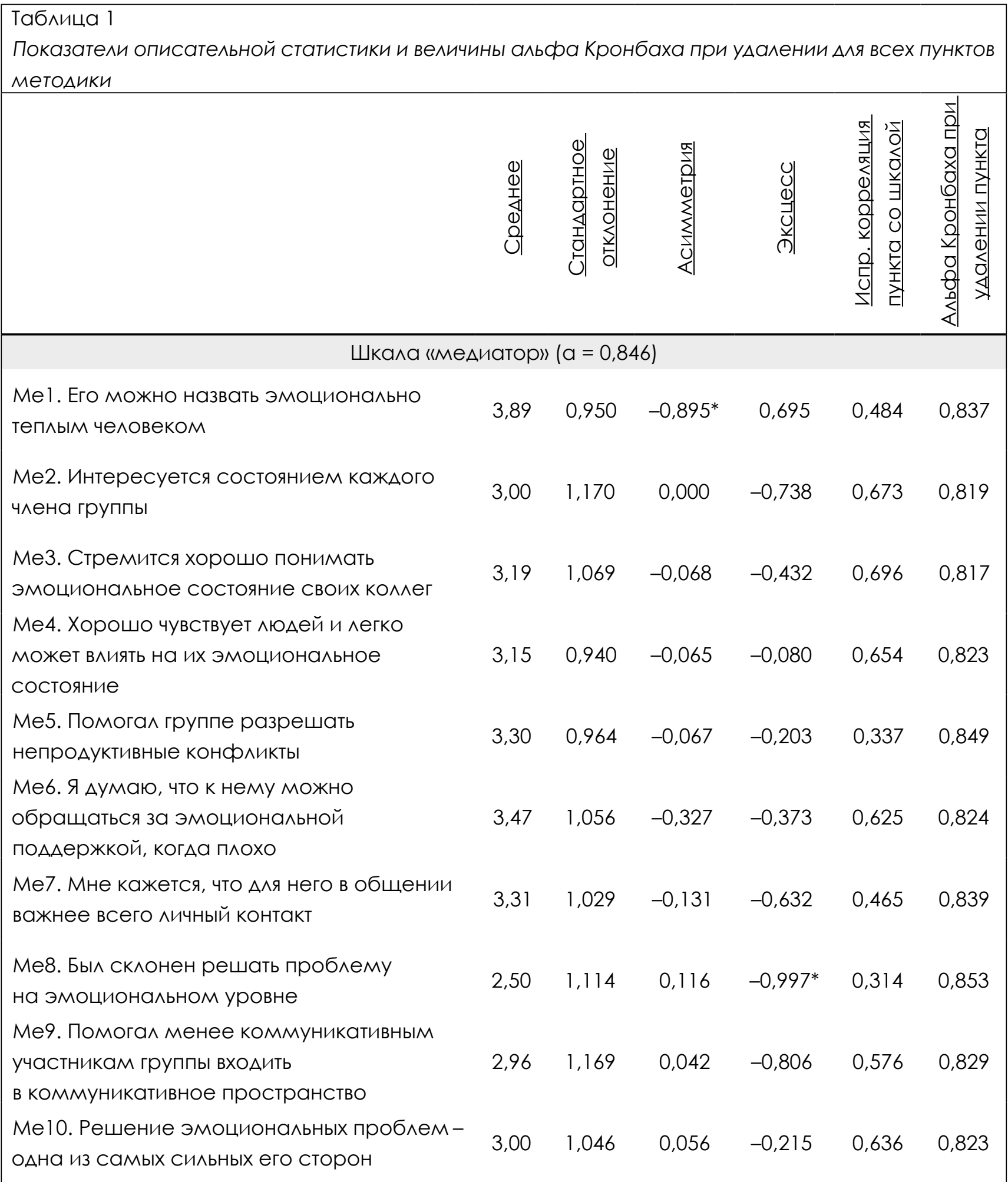


БАЗАРОВ Т. Ю., РАЙКОВ А. В., ШАЙХУТДИНОВ Р. Р.

ВОЗМОЖНОСТИ И ОГРАНИЧЕНИЯ ОПРОСНИКА «МАСТЕР ОРГАНИЗАЦИИ ГРУППОВОЙ РАБОТЫ»

Российский психологИчЕский жУРнАл, 2019, Т. 16, № 4, 56-73. doi: 10.21702/rpj.2019.4.5

СОЦИАЛЬНАЯ ПСИХОЛОГИЯ

\begin{tabular}{|c|c|c|c|c|c|c|}
\hline $\begin{array}{l}\text { Таблица } 1 \\
\text { Показатели описательной статистики и велич } \\
\text { методики }\end{array}$ & $-ы a \wedge b$ & $\mathrm{Kpc}$ & axa пр & Аалени & $\wedge я$ всех & /HKTOB \\
\hline & 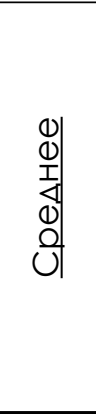 & 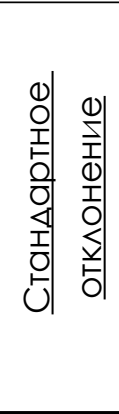 & 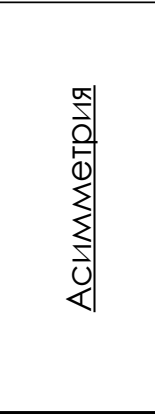 & 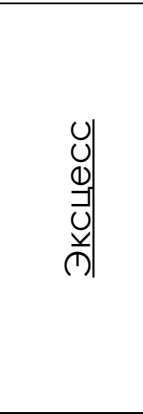 & 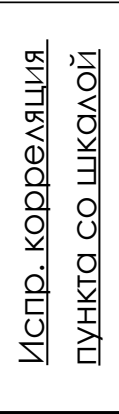 & 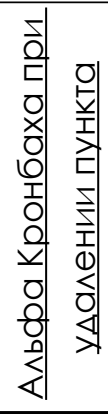 \\
\hline Шкала «моА & раток & $l a=0$ & 54) & & & \\
\hline $\begin{array}{l}\text { Мо1. Может быстро выявлять и использовать } \\
\text { новые способы в решении залачи }\end{array}$ & 3,55 & 1,035 & $-0,404$ & $-0,360$ & 0,590 & 0,838 \\
\hline $\begin{array}{l}\text { Мо2. ^огика - онна из самых сильных его } \\
\text { сторон }\end{array}$ & 3,5 & 0,929 & $-0,362$ & 0,259 & 0,513 & 0,844 \\
\hline Мо3. Умеет так залавать вопросы, что ^юли & & & & & & \\
\hline $\begin{array}{l}\text { после ответа на них сами находят верное } \\
\text { решение своей проблемы }\end{array}$ & 2,81 & 1,079 & $-0,027$ & $-0,582$ & 0,549 & 0,841 \\
\hline Mo4. Всегла начинает дискуссию, чтобы & & & & & & \\
\hline $\begin{array}{l}\text { стимулировать коллег на новые мысли } \\
\text { и привести группу в Авижение }\end{array}$ & 3,64 & 1,007 & $-0,918^{*}$ & 0,700 & 0,516 & 0,844 \\
\hline $\begin{array}{l}\text { Мо5. Быстро и ^егко переключается } \\
\text { с решения одной залачи на Аругую }\end{array}$ & 4,19 & 0,837 & $-0,917^{*}$ & 0,400 & 0,305 & 0,859 \\
\hline $\begin{array}{l}\text { Мо6. Хорошо в^алеет изложением сути } \\
\text { проблемы }\end{array}$ & 3,75 & 1,036 & $-0,696^{*}$ & 0,029 & 0,695 & 0,828 \\
\hline $\begin{array}{l}\text { Мо7. Занимается орормулировкой } \\
\text { проблемных вопросов }\end{array}$ & 3,51 & 1,076 & $-0,675^{*}$ & $-0,017$ & 0,572 & 0,839 \\
\hline $\begin{array}{l}\text { Мо8. Четко орормулирует и высказывает } \\
\text { илеи }\end{array}$ & 3,84 & 0,998 & $-0,846^{*}$ & 0,541 & 0,688 & 0,829 \\
\hline $\begin{array}{l}\text { Мо9. Стимулировал участников } \\
\text { на вопросы и комментарии }\end{array}$ & 3,35 & 1,142 & $-0,606^{*}$ & $-0,541$ & 0,537 & 0,843 \\
\hline $\begin{array}{l}\text { Мо10. Вылвига^ большое количество илей } \\
\text { решения проблемы }\end{array}$ & 3,62 & 1,109 & $-0,651^{*}$ & $-0,382$ & 0,602 & 0,836 \\
\hline Стандартная ошибка & & & 0,246 & 0,488 & & \\
\hline
\end{tabular}


БАЗАРОВ Т. Ю., РАЙКОВ А. В., ШАЙХУТДИНОВ Р. Р.

ВОЗМОЖНОСТИ И ОГРАНИЧЕНИЯ ОПРОСНИКА «МАСТЕР ОРГАНИЗАЦИИ ГРУППОВОЙ РАБОТЫ»

РосСИЙСКИЙ пСИХОЛОГИЧЕСКИЙ ЖУРнАл, 2019, Т. 16, № 4, 56-73. doi: 10.21702/rpj.2019.4.5

СОЦИАЛЬНАЯ ПСИХОЛОГИЯ

Шкальные баллы вычислялись путем усреднения ответов испытуемого на пункты шкалы. Статистики шкальных баллов обобщены в таблице 2.

\begin{tabular}{|c|c|c|c|c|c|c|c|}
\hline \multicolumn{8}{|c|}{$\begin{array}{l}\text { Таблица } 2 \\
\text { Показатели описательнои } \\
\text { бамлов методики (N = 95) }\end{array}$} \\
\hline & 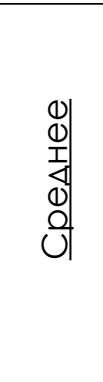 & 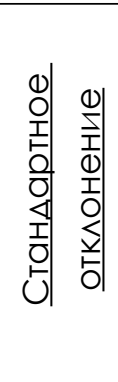 & $\sum_{\substack{\leq \\
\vdots}}^{\substack{1 \\
\sum}}$ & 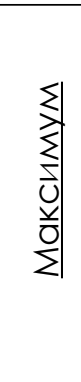 & 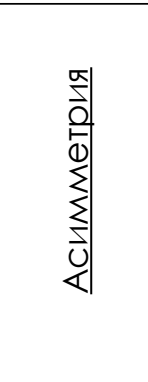 & 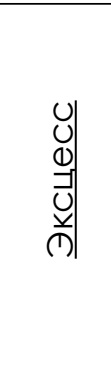 & 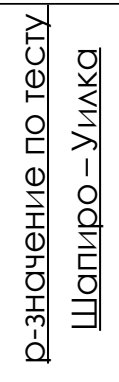 \\
\hline Фасилитатор & 3,24 & 0,749 & 1 & 5 & $-0,555^{*}$ & 0,638 & 0,034 \\
\hline Медиатор & 3,16 & 0,658 & 1,3 & 4,8 & $-0,058$ & 0,309 & 0,752 \\
\hline \multirow[t]{2}{*}{ модератор } & 3,56 & 0,662 & 1,5 & 4,8 & $-0,598^{*}$ & 0,915 & 0,007 \\
\hline & \multicolumn{4}{|c|}{ Стандартная ошибка } & 0,247 & 0,490 & \\
\hline
\end{tabular}

Условные обозначения: * - значение превышает две свои стандартные ошибки по модулю.

Шкалы «фасилитатор» и «модератор» обладают значимым скосом к сравнительно высоким баллам, что может объясняться как спецификой задачи для командного интеллектуального обсуждения, так и возможной социальной желательностью качеств. Распределение по шкале «медиатор» не отличается от нормального, что доказывает достаточную репрезентативность выборки для этого параметра.

\section{Структурное моделирование}

Для проверки надежности и факторной валидности шкал опросника был использован конфирматорный факторный анализ. Проведение метода на нашей выборке проблематично: во-первых, количество испытуемых невелико для структурного моделирования (Tabachnick \& Fidell, 2014), во-вторых, шкалу Лайкерта по пунктам следует рассматривать лишь как ранговую категориальную. Чтобы повысить доверие к выводам, мы вели расчет дважды, с помощью: а) оптимальной для малых выборок статистики Юаня - Бентлера (Tabachnick \& Fidell, 2014), б) анализа категориальных переменных (Bentler, 2006).

Согласованность модели с эмпирическими данными, согласно подходу Юаня - Бентлера, можно считать лишь умеренной $\left(\chi^{2}=638,18, d f=402 ; \mathrm{CFI}=0,759 ; \mathrm{RMSEA}=0,079\right)$. Если отношение $\chi^{2}$ к степеням свободы укладывается в 2 (Митина, 2008), а величина RMSEA ниже 0,1 не позволяет говорить о плохой согласованности (Tabachnick \& Fidell, 2014), то сравнительный индекс согласия далек от требуемого уровня 0,9 (Tabachnick \& Fidell, 2014; Митина, 2008). Расчеты на основе категориальных переменных говорят о хорошей согласованности модели с данными $\left(\chi^{2}=646,548, C F I=0,941 ; \operatorname{RMSEA}=0,080\right)$. 
БАЗАРОВ Т. Ю., РАЙКОВ А. В., ШАЙХУТДИНОВ Р. Р.

ВОЗМОЖНОСТИ И ОГРАНИЧЕНИЯ ОПРОСНИКА «МАСТЕР ОРГАНИЗАЦИИ ГРУППОВОЙ РАБОТЫ»

РосСиЙский психологИчЕский жУРнАл, 2019, Т. 16, № 4, 56-73. doi: 10.21702/rpj.2019.4.5

СОЦИАЛЬНАЯ ПСИХОЛОГИЯ

При обеих проверках все пункты опросника продемонстрировали значимую положительную нагрузку на соответствующие им факторы $(z \geq 2,06 ; p<0,02)$. Кроме того, все латентные переменные обладали значимой $(z \geq 10 ; p<0,0005)$ и очень высокой корреляцией между собой (табл. 3).

\begin{tabular}{|c|c|c|c|c|}
\hline \multirow[b]{2}{*}{ Методология } & \multicolumn{2}{|c|}{ Медиатор } & \multicolumn{2}{|c|}{ Молератор } \\
\hline & $\begin{array}{c}\text { Статистика } \\
\text { Юаня- } \\
\text { Бентлера }\end{array}$ & $\begin{array}{c}\text { Полихорическая } \\
\text { корреляция }\end{array}$ & $\begin{array}{c}\text { Статистика } \\
\text { Юаня- } \\
\text { Бентлера }\end{array}$ & $\begin{array}{c}\text { Полихорическая } \\
\text { корреляция }\end{array}$ \\
\hline Фаси^итатор & 0,772 & 0,779 & 0,817 & 0,797 \\
\hline Медиатор & & & 0,706 & 0,706 \\
\hline
\end{tabular}

Высокая взаимосвязь между шкалами делает актуальным доказательство факторной валидности. Для этой цели была проверена конкурирующая модель № 2, в которой корреляции между факторами приравнены к 1, соответствуя тождеству всех ролей мастера групповой работы. Различия в согласованности вложенных моделей были оценены с помощью критерия различий хи-квадрат (Byrne, 2010) и информационных критериев (Garson, 2015), все они обладают крайне высокой значимостью ( $p<0,00001)$ и обобщены в таблице 4.

\begin{tabular}{|c|c|c|c|c|c|c|c|}
\hline \multicolumn{8}{|l|}{$\begin{array}{l}\text { Таблица } 4 \\
\text { Согласова }\end{array}$} \\
\hline & \multirow{2}{*}{$\underline{d f}$} & \multicolumn{5}{|c|}{ ИнАеКсЫ СОГАасованноСТИ МОАеАИ } & \multirow{4}{*}{$\underline{\text { Разность } \chi^{2}}$} \\
\hline & & $\underline{\mathrm{CFI}}$ & RMSEA & $\chi^{2}$ & $\underline{\mathrm{AIC}}$ & CAIC & \\
\hline & & 0,759 & 0,079 & 638,175 & $-165,825$ & $-1598,693$ & \\
\hline & & 0,941 & 0,080 & 646,548 & $-157,452$ & $-1590,320$ & \\
\hline \multirow{2}{*}{ 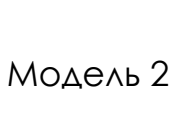 } & \multirow{2}{*}{405} & 0,690 & 0,089 & 708,653 & $-101,347$ & $-1544,908$ & 70,478 \\
\hline & & 0,903 & 0,102 & 805,485 & $-4,515$ & $-1448,076$ & 158,937 \\
\hline
\end{tabular}

Таким образом, шкалы нашего опросника ролей мастера групповой работы обладают исключительно высокой дискриминантной валидностью, эмпирически доказывая специфичность и обособленность выделенных конструктов - фасилитатора, медиатора и модератора. 
БАЗАРОВ Т. Ю., РАЙКОВ А. В., ШАЙХУТДИНОВ Р. Р.

ВОЗМОЖНОСТИ И ОГРАНИЧЕНИЯ ОПРОСНИКА «МАСТЕР ОРГАНИЗАЦИИ ГРУППОВОЙ РАБОТЫ॥

РосСИЙСКИЙ пСИХОЛОГИЧЕСКИЙ ЖУРнАл, 2019, Т. 16, № 4, 56-73. doi: 10.21702/rpj.2019.4.5

СОЦИАЛЬНАЯ ПСИХОЛОГИЯ

Затем был проведен ЛМ-тест, на базе которого было выбрано 5 наиболее значимых и интерпретируемых детерминаций пунктов побочными факторами, в связи с чем приняты решения о переформулировках заданий (табл. 5).

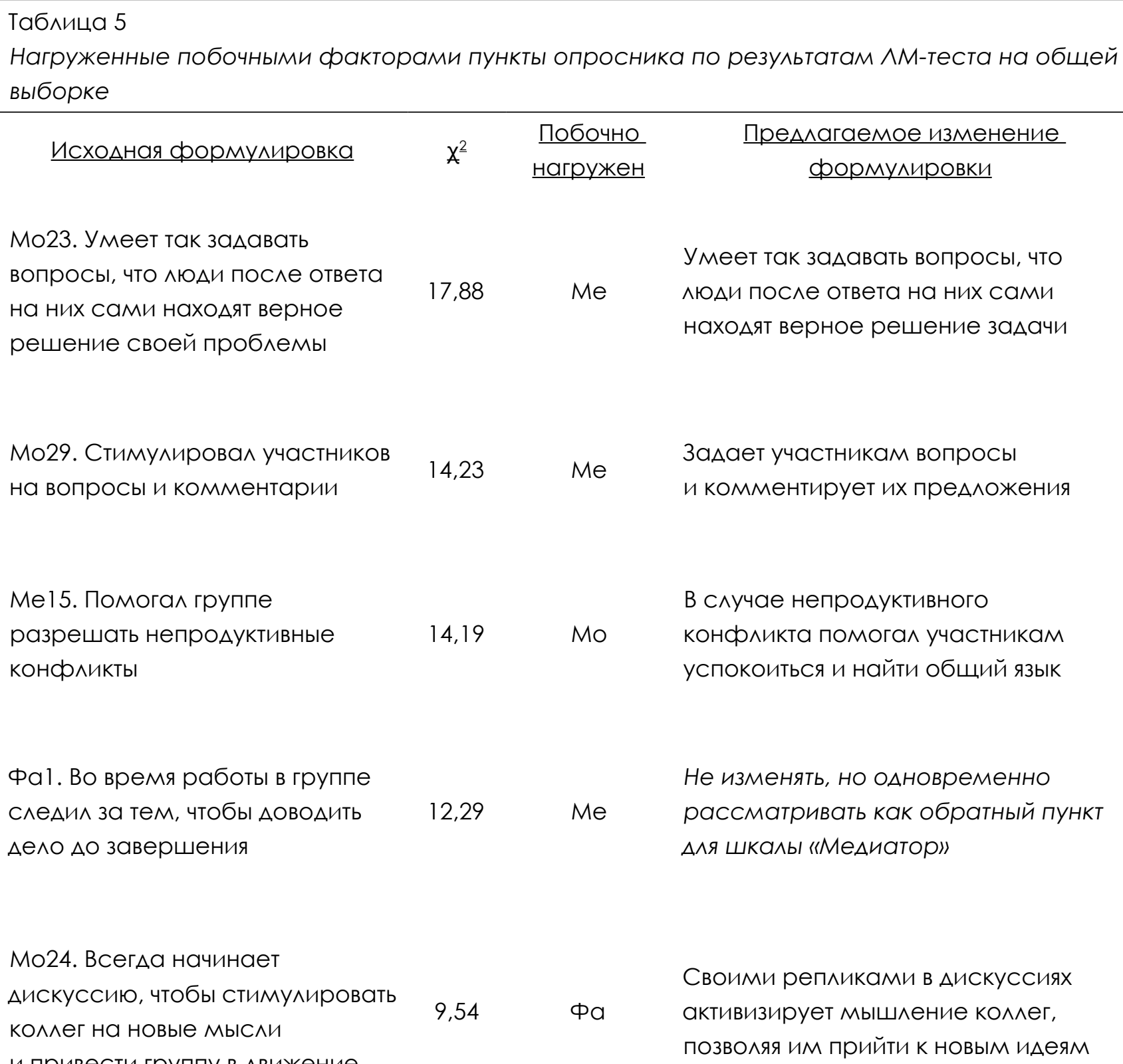

Исходная фоормулировка

Мо23. Умеет так залавать вопросы, что ^юАИ после ответа на них сами нахо $А$ ят верное решение своей проблемы

Мо29. Стимулировал участников на вопросы и комментарии

ме15. Помогал группе разрешать непродуктивные конфрликты

Фа1. Во время работы в группе С^еАИ^ за тем, чтобы АОВОАИть

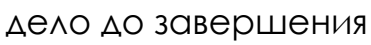

Мо24. Всегла начинает Аискуссию, чтобы стимулировать комлег на новые мысли $9,54 \quad \Phi a$

Умеет так залавать вопросы, что 17,88 Ме мюАи после ответа на них сами находят верное решение залачи

14,23 Me

Задает участникам вопросы и комментирует их преАложения

В случае непродуктивного 14,19 Мо конфмикта помогал участникам успокоиться и найти общий язык

Не изменять, но одновременно 12,29 Ме рассматривать как обратный пункт Аля шкалы «Медиатор»

\section{Своими репликами в Аискуссиях} активизирует мышление комлег, позволяя им прийти к новым иАеям

и привести группу в Авижение

Далее был проведен конфирматорный факторный анализ данных, ограниченный выборкой участников (72 человека), исключая лидеров группы. 
БАЗАРОВ Т. Ю., РАЙКОВ А. В., ШАЙХУТДИНОВ Р. Р.

ВОЗМОЖНОСТИ И ОГРАНИЧЕНИЯ ОПРОСНИКА «МАСТЕР ОРГАНИЗАЦИИ ГРУППОВОЙ РАБОТЫ»

РосСиЙский психологИчЕский жУРнАл, 2019, Т. 16, № 4, 56-73. doi: 10.21702/rpj.2019.4.5

СОЦИАЛЬНАЯ ПСИХОЛОГИЯ

Согласованность модели с эмпирическими данными, согласно подходу Юаня - Бентлера может считаться лишь умеренно приемлемой $\left(\chi^{2}=601,023, d f=402 ; C F I=0,760 ;\right.$ RMSEA = 0,084). Расчеты на основе полихорической корреляции ранговых шкал утверждают об очень хорошей согласованности модели с данными $\left(\chi^{2}=454,738, \mathrm{CFI}=0,981 ; \mathrm{RMSEA}=0,043\right)$.

При обеих проверках все пункты продемонстрировали значимую положительную нагрузку на их факторы $(z \geq 2,06 ; p<0,02)$. Все факторы обладали значимой $(z \geq 10 ; p<0,0005)$ высокой корреляцией между собой (см. табл. 6). Результаты сходны с общей выборкой, повышая к ним доверие.

\begin{tabular}{|c|c|c|c|c|}
\hline \multirow[b]{2}{*}{ Методология } & \multicolumn{2}{|c|}{ Медиатор } & \multicolumn{2}{|c|}{ Mo_epatop } \\
\hline & $\begin{array}{c}\text { Статистика } \\
\text { Юаня - } \\
\text { Бентлера }\end{array}$ & $\begin{array}{c}\text { Полихорическая } \\
\text { корреляция }\end{array}$ & $\begin{array}{c}\text { Статистика } \\
\text { Юаня- } \\
\text { Бентлера }\end{array}$ & $\begin{array}{c}\text { Полихорическая } \\
\text { корреляция }\end{array}$ \\
\hline Фасилитатор & 0,759 & 0,756 & 0,793 & 0,750 \\
\hline Медиатор & & & 0,724 & 0,711 \\
\hline
\end{tabular}

\section{Валидность методики}

Содержательная валидность опросника достигается составлением формулировок в соответствии с теоретически выделенными задачами и способами выполнения трех ролей мастера групповой работы.

О конвергентной валидности шкал опросника можно предварительно судить по их взаимосвязям со шкальными баллами по другим методикам, пройденным респондентами. Нами были выдвинуты следующие гипотезы:

1. Уровни общегрупповой мотивации, групповой сплоченности и психологической атмосферы в коллективе прямо связаны с выраженностью всех ролей, но наиболее - с выраженностью роли медиатора.

2. Выраженность роли фасилитатора прямо связана с деловым климатом, предметно-деятельностной и социально-психологической сплоченностью, но последняя связана с ней слабее, чем с ролью медиатора.

3. Выраженность роли медиатора прямо связана с деловым климатом, нравственным климатом, социально-психологической сплоченностью.

4. Выраженность роли модератора прямо связана с творческим климатом, предметно-деятельностной сплоченностью и нравственным климатом, но последний связан с ней слабее, чем с ролью медиатора. 
БАЗАРОВ Т. Ю., РАЙКОВ А. В., ШАЙХУТДИНОВ Р. Р.

ВОЗМОЖНОСТИ И ОГРАНИЧЕНИЯ ОПРОСНИКА «МАСТЕР ОРГАНИЗАЦИИ ГРУППОВОЙ РАБОТЫ॥

РосСИЙСКИЙ пСИХОЛОГИЧЕСКИЙ ЖУРнАл, 2019, Т. 16, № 4, 56-73. doi: 10.21702/rpj.2019.4.5

СОЦИАЛЬНАЯ ПСИХОЛОГИЯ

Статистики шкал валидизирующих показателей обобщены в таблице 7.

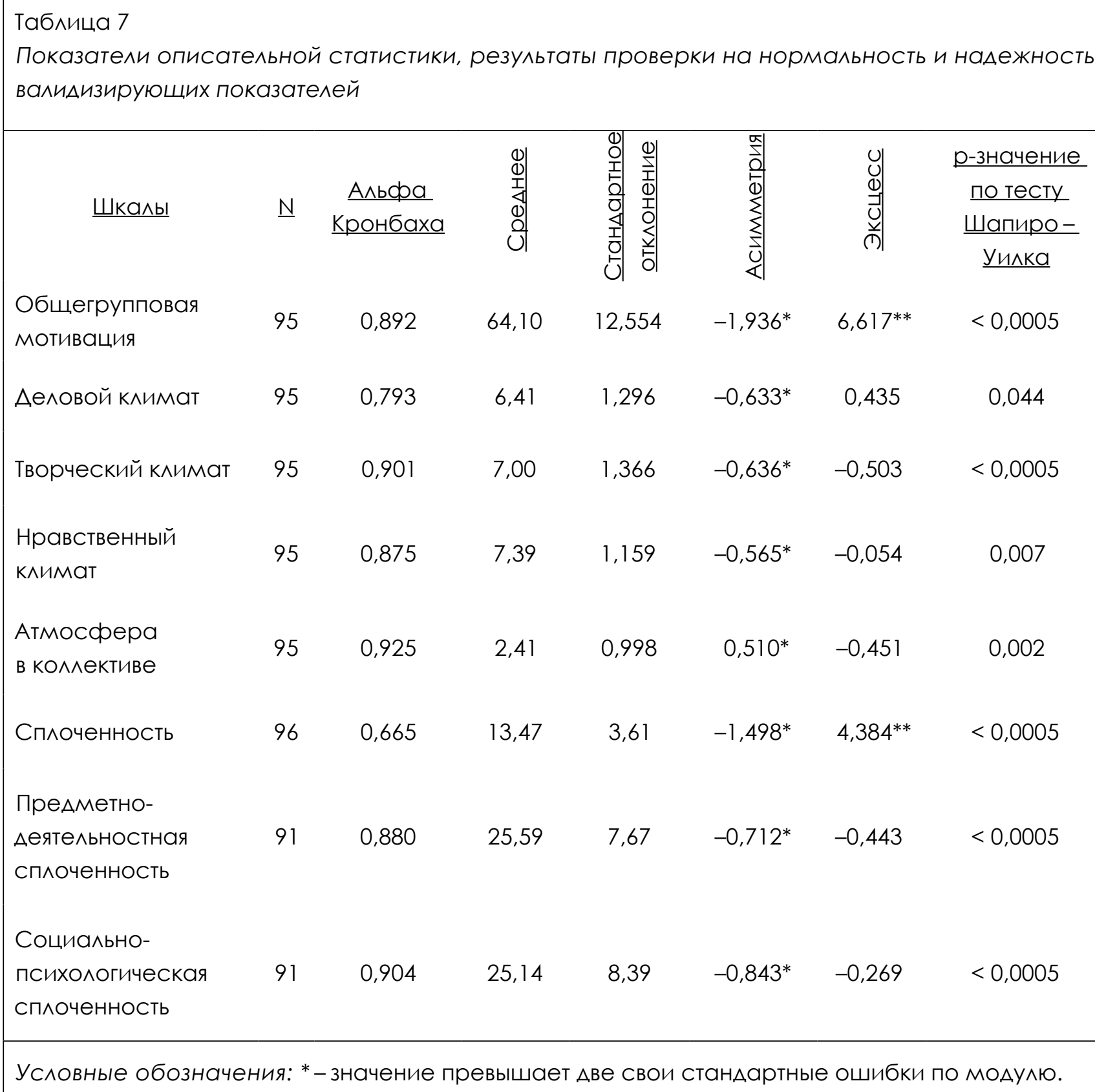

Все используемые для валидизации шкалы высоко надежны. Из-за ненормальности распределения в качестве основного применялись непараметрические коэффициенты корреляции Спирмена (табл. 8). 
БАЗАРОВ Т. Ю., РАЙКОВ А. В., ШАЙХУТДИНОВ Р. Р.

ВОЗМОЖНОСТИ И ОГРАНИЧЕНИЯ ОПРОСНИКА «МАСТЕР ОРГАНИЗАЦИИ ГРУППОВОЙ РАБОТЫ»

РосСиЙский психологИчЕский жУРнАл, 2019, Т. 16, № 4, 56-73. doi: 10.21702/rpj.2019.4.5

СОЦИАЛЬНАЯ ПСИХОЛОГИЯ

\begin{tabular}{|c|c|c|c|}
\hline $\begin{array}{l}\text { Таблица } 8 \\
\text { Коэфрорициенты корреляции между шкалам } \\
\text { методик }\end{array}$ & иетодики «ФаМ & 》 и шкалами & иилизирующи \\
\hline & Шкал & ТОАИКИ «Фа & Moly \\
\hline & & & \\
\hline & 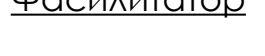 & Tentive & 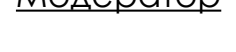 \\
\hline Общегрупповая мотивация & $0,430^{* * *}$ & $0,572^{* * *}$ & $0,507^{* * *}$ \\
\hline Групповая сп^оченность & $0,315^{* * *}$ & $0,417^{* * *}$ & $0,369 * * *$ \\
\hline Психологическая атмосорера & $-0,463^{* * *}$ & $-0,459 * * *$ & $-0,465^{* * *}$ \\
\hline Предметно-Аеятельностная сп^оченность & $0,208^{*}$ & $0,396^{* * *}$ & $0,250^{* *}$ \\
\hline Социально-психологическая сп^оченность & $0,228^{* *}$ & $0,398^{* * *}$ & $0,244^{* *}$ \\
\hline Аеловой климат & $0,331^{* * *}$ & $0,401^{* * *}$ & $0,420 * * *$ \\
\hline Творческий климат & $0,416^{* * *}$ & $0,391^{* * *}$ & $0,505^{* * *}$ \\
\hline Нравственный климат & $0,381^{* * *}$ & $0,424^{* * *}$ & $0,479^{* * *}$ \\
\hline
\end{tabular}

Как видно из полученных данных, психологическая атмосфера в группе проявила приблизительно равную связь с выраженностью всех ролей мастера групповой работы, что может объясняться спецификой групповой деятельности. При решении задач на продуктивное мышление в формате регламентированной процедуры компетентности фасилитатора и модератора могли быть важными для благоприятной групповой атмосферы.

Роль фасилитатора оказалась связанной, хотя и незначительно, с показателями предметно-деятельностной сплоченности. Возможно, специфика деятельности способствовала большему сплочению группы вокруг генератора идей. Все обнаруженные связи значимы, но посредническая и психотерапевтическая функции лидера оказались главными для всех аспектов сплоченности, включая предметно-деятельностную.

Валидность по полу. Предполагалось, что медиативная функция мастера организации групповой работы, ориентированная на эмоциональный аспект взаимодействия, в большей 
БАЗАРОВ Т. Ю., РАЙКОВ А. В., ШАЙХУТДИНОВ Р. Р.

ВОЗМОЖНОСТИ И ОГРАНИЧЕНИЯ ОПРОСНИКА «МАСТЕР ОРГАНИЗАЦИИ ГРУППОВОЙ РАБОТЫ»

РосСиЙскИй псИХологИЧЕСКИЙ ЖУРнАл, 2019, Т. 16, № 4, 56-73. doi: 10.21702/rpj.2019.4.5

СОЦИАЛЬНАЯ ПСИХОЛОГИЯ

мере должна быть свойственна лидерам-женщинам. Тест Манна -Уитни (U = 844; $p=0,027$; $r=0,227)$, действительно, подтверждает наличие слабой связи. Однако выраженность ролей фасилитатора и модератора половой специфики не имеет $(U \geq 977,5 ; p \geq 0,220 ; r<0,1)$.

\section{Обсуждение результатов}

В ходе эмпирического исследования был разработан и апробирован диагностический инструмент, который продемонстрировал хорошие психометрические показатели. Все шкалы опросника обладают высоким уровнем надежности-согласованности, в них не было выявлено явно неинформативных для поставленной цели заданий. В то же время статистические данные выявили необходимость переформулировки некоторых утверждений, что позволило усовершенствовать исходный материал. Имеются убедительные основания говорить о факторной валидности структуры опросника, выступающие эмпирической поддержкой концепции о наличии трех самостоятельных и несводимых друг к другу, хотя и тесно взаимосвязанных, ролях мастера организации групповой работы.

Кроме того, получен ряд доказательств конвергентной валидности и валидности методики по полу, свидетельствующих о способности инструмента к дифференциации объективно существующих различий.

\section{Заключение}

Перспективу данного исследования мы видим в практическом использовании разработанной методики в сфере управления и подготовке специалистов в области организации групповой работы.

Необходимо отметить специфику выборки для апробации и особенности содержания совместной деятельности испытуемых (решение творческих и проблемных задач). Ради обеспечения большей репрезентативности данных необходимы дальнейшие исследования на других выборках и в иных условиях взаимодействия, многократное увеличение числа опрошенных на основной этап апробации.

Следует также отметить, что распределение данных по ряду пунктов, а также шкалам «фасилитатор» и «модератор» обладало скосом к сравнительно более высоким баллам, что может быть вызвано как неполной репрезентативностью данных, так и, возможно, социальной желательностью этих черт, которую следует учитывать при диагностическом использовании методики.

Возможность диагностического использования опросника, разумеется, подразумевает расчет тестовых норм. Стандартизация модифицированной методики «Фасилитатор - Медиатор Модератор», наряду с расширением доказательств ее надежности, валидности и репрезентативности, является важнейшей перспективой будущих исследований.

\section{Литература}

Базаров, Т. Ю. (2011). Технология центров оценки персонала: процессы и результаты: практическое пособие. Москва: КноРус.

Базаров, Т. Ю. (2013). Бизнес-образование: развитие организаций или организация развития? Организационная психология, 3(4), 92-108.

Базаров, Т. Ю. (2017). Влияние индивидуально-психологических характеристик членов группы на успешность совместно-творческой деятельности. В Н. Л. Иванова (отв. ред.), 
БАЗАРОВ Т. Ю., РАЙКОВ А. В., ШАЙХУТДИНОВ Р. Р.

ВОЗМОЖНОСТИ И ОГРАНИЧЕНИЯ ОПРОСНИКА «МАСТЕР ОРГАНИЗАЦИИ ГРУППОВОЙ РАБОТЫ»

РосСиЙский психологИчЕский жУРнАл, 2019, Т. 16, № 4, 56-73. doi: 10.21702/rpj.2019.4.5

СОЦИАЛЬНАЯ ПСИХОЛОГИЯ

Бизнес-психология в международной перспективе: коллективная монография. Москва: Университетская книга.

Базаров, Т. Ю. и Еремин, Б. Л. (ред.) (2006). Управление персоналом. Учебник для вузов. Москва: ЮНИТИ-ДАНА.

Базаров, Т. Ю. и Ладионенко, М. А. (2013). Методика создания модели компетентностей. Организационная психология, 3(3), 61-77.

Базаров, Т. Ю. и Ладионенко, М. А. (2017). Технологические основы оценки персонала (методические рекомендации к курсу «Ассессмент-центр»). Москва: Перо.

Базаров, Т. Ю. и Чиннова, А. С. (2012). Социально-психологические детерминанты эффективности медиации. Психологические исследования, 5(23), 11. Доступ 20 июня 2019, источник http://psystudy.ru/index.php/num/2012v5n23/676-bazarov23.html

Белбин, Р. М. (2007). Команды менеджеров: как объяснить их успех или неудачу (2-е изд.). Лондон: Кивитс.

Богданов, В. В. (2012). Управление проектами. Корпоративная система - шаг за шагом. Москва: Манн, Иванов и Фербер.

Бояцис, Р. и Макки, Э. (2007). Резонансное лидерство (А. Лисицина, пер. с англ.). Москва: Альпина Бизнес Букс.

Журавлев, А. Л. (2005). Психология совместной деятельности. Москва: Ин-т психологии РАН.

Кричевский, Р. Л. (1993). Если Вы - руководитель... Элементы психологии менеджмента в повседневной работе. Москва: Дело.

Ладанов, И. Д. (2004). Практический менеджмент. Психотехника управления и самотренировки. Москва: Корпоративные стратегии.

Мартынова, А. В. (2011). Фасилитация как технология организационного развития и изменений. Организационная психология, 1(2), 53-91.

Митина, О. В. (2008). Моделирование латентных изменений с помощью структурных уравнений. Экспериментальная психология, 1(1), 131-148.

Митина, О. В. (2011). Разработка и адаптация психологических опросников. Москва: Смысл.

Разу, М. (2011). Управление проектом. Основы проектного управления. Москва: КноРус.

Русанова, И. И. (1992). Что? Где? Когда? Игра для всех. Москва: Русский язык.

Сидоренков, А. В. и Мондрус, А. Л. (2011). Методика изучения сплоченности малой группы в организации: Учебно-методическое пособие. Ростов-на-Дону: Изд-во ЮФУ.

Сорина, Г.В.(2006). Аргументативные практики и вопросно-ответные процедуры в управленческом дискурсе. Мысль: Журнал Петербургского философского общества, 6(1), 160-174.

Фетискин, Н. П., Козлов, В. В. и Мануйлов, Г. М. (2002). Социально-психологическая диагностика развития личности и малых групп. Москва: Изд-во Института психотерапии.

Штроо, В. А. (2015). Методы активного сочиально-психологического обучения. Москва: Юрайт.

Штроо, В. А. и Серов, С. Ю. (2011). Эмоциональный интеллект участников как фактор эффективности деловых переговоров. Организационная психология, 1(1), 8-23.

Bens, I. (2005). Advanced Facilitating Strategies: Tools \& techniques to master difficult situations. San Francisco: Jossey-Bass.

Bentler, P. M. (2006). EQS 6 structural equations program manual. Encino, CA: Multivariate Software, Inc. Byrne, B. M. (2010). Structural equation modeling with AMOS: Basic concepts, applications, and programming (2nd ed.). New York: Routledge.

Garson, G. D. (2015). Structural equation modeling. North Carolina: Statistical Publishing Associates. 
Howard, A., \& Bray, D. (1990). Predictions of managerial success over long periods of time: Lessons from the management progress study. In K. E. Clark \& M. B. Clark (Eds.), Measures of leadership. Greensboro: Center for Creative Leadership.

Schwarz, R. (2005). The skilled facilitator approach. In S. Schuman (Ed.), The IAF handbook of group facilitation (pp. 21-34). San Francisco: Jossey-Bass.

Tabachnick, B. G., \& Fidell, L. S. (2014). Using Multivariate Statistics (6th ed.). Northridge: Pearson.

\section{Конфликт интересов отсутствует}

